\title{
Large osteochondroma of the coronoid process of left mandible: clinical and imaging findings of a rare
}

\section{case}

\begin{abstract}
Osteochondroma (OC) is the most common benign tumor of the skeleton which having both chondroma and osteoma. This tumor generally found on the metaphysis of long bones and occurs very rarely in the maxillofacial region. In maxillofacial region, condyle and coronoid process of the mandible are the most commonly affected areas. When it is sited in the coronoid process, it causes progressive facial asymmetry and limitation of mouth opening. In this case report we present a rare case of osteochondroma of left condyle region in a 69 -year-old male patient attendance by limited mouth opening.
\end{abstract}

Keywords: osteochondroma, coronoid process, CBCT

\author{
Volume 7 Issue 2 - 2017 \\ Selin Yesiltepe,' Ibrahim Sevki Bayrakdar,'2 \\ Hayati Murat Akgül,' Ahmet Berhan Yilmaz,' \\ Suayip Burak Duman ${ }^{3}$ \\ 'Department of Dentomaxillofacial Radiology, Ataturk \\ University, Turkey \\ ${ }^{2}$ Department of Dentomaxillofacial Radiology, Osmangazi \\ University, Turkey \\ ${ }^{3}$ Department of Oral and Maxillofacial Radiology, Inonï \\ University, Turkey
}

\begin{abstract}
Correspondence: Ibrahim Sevki Bayrakdar, Department of Oral and Maxillofacial Radiology, Faculty of Dentistry, Osmangazi University, Turkey, Tel 0090222 2391303, Fax 0090 222 2391273, Email ibrahimsevkibayrakdar@gmail.com
\end{abstract}

Received: July 05, 2017 | Published: August 0I, 2017
Abbreviations: OC, osteochondroma; $\mathrm{CBCT}$, cone beam computed tomography; $3 \mathrm{D}$, three-dimensional; $\mathrm{CT}$, computed tomography

\section{Introduction}

Osteochondroma (OC) is the most common benign tumor in the axial and appendicular skeleton. It accounts for $\% 35-50$ of all benign bone tumors and $\% 8-15$ of all primary bone tumors. The World Health Organization describes the $\mathrm{OC}$ as a cartilage-capped bony protrusion on the external surface of bone. ${ }^{1}$ Although Von Langenbeck defined coronoid process hyperplasia in 1853, Jacob first described OC of the coronoid process forming pseudojoint between the coronoid process and the zygoma in 1899 , now it was known as Jacob disease. ${ }^{2}$

This benign skeletal tumor is frequently located at the level of the metaphysis of long bones and occurs rarely in the oral and maxillofacial region. OC is commonly seen coronoid and condylar processes of the mandible within the facial bones. ${ }^{3}$ The tumour grows slowly and it causes progressive limitation of mouth opening and facial asymmetry when it is sited in the coronoid process. ${ }^{4}$ Another symptoms are remodeling, devastation or expansion at the zygoma and/or zygomatic arch or pain with mouth opening. ${ }^{5}$

Clinical examination, radiography and cone beam computed tomography $(\mathrm{CBCT})$ is useful diagnostic tools for OC. In the radiologic diagnosis, panoramic radiography and Water' sprojection are useful that can show an expanded coronoid process. ${ }^{6}$ CBCT is the gold standard for exact diagnosis because it provides anatomical details. The facial asymmetry and limitation of mouth opening are determinative of the need for surgical removal of the lesion. The excision of the coronoid process with the tumor is the precise treatment. ${ }^{7}$ After excision, the recurrence rate is very low $(\% 2){ }^{8}$ In this case report, we present details of the patient with OC of coronoid process attendance by limited mouth opening.

\section{Case presentation}

A 69-year-old male patient referred to the radiology clinic of the Atatürk University with complaint limitation of mouth opening, with no evidence of pain or joint sound. There was no history of facial trauma and medical history was not significant. In clinical examination, limitation of mouth opening and deviation to the left side during the mouth openning was found in patient. Figure 1 Panoramic radiography showed expanded irregularly shaped radiopaque lesion on the left coronoid process. Figure 2 CBCT scan was performed. Three-dimensional (3D) reconstruction of the CBCT images showed a mushroomshaped hyperplastic enlargement of the coronoid process which causesresorption under the bones of the skull base. Figure 3 The size of the lesion was measured $33,1 \times 25,5 \times 30,2 \mathrm{~mm}$. Patient was referrred to the surgery clinic with the prediagnosis of osteochondroma.
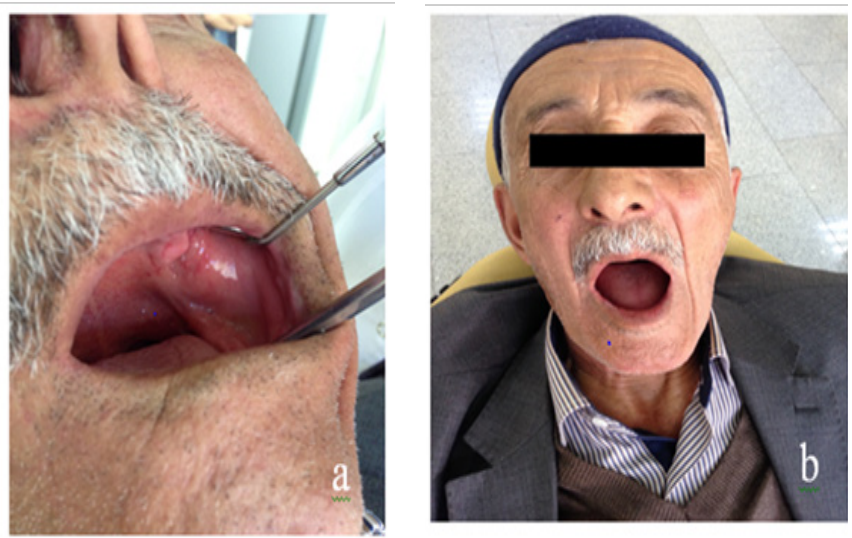

Figure I showes A) limitation of mouth opening B) deviation to the left side during the mouth opening. 


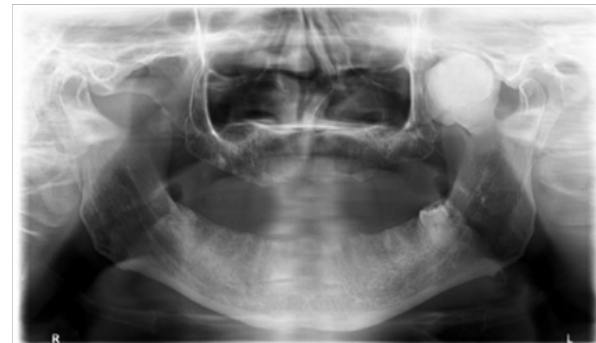

Figure 2 Panoramic radiography showes expanded irregularly shaped radiopaque lesion on the left coronoid process.
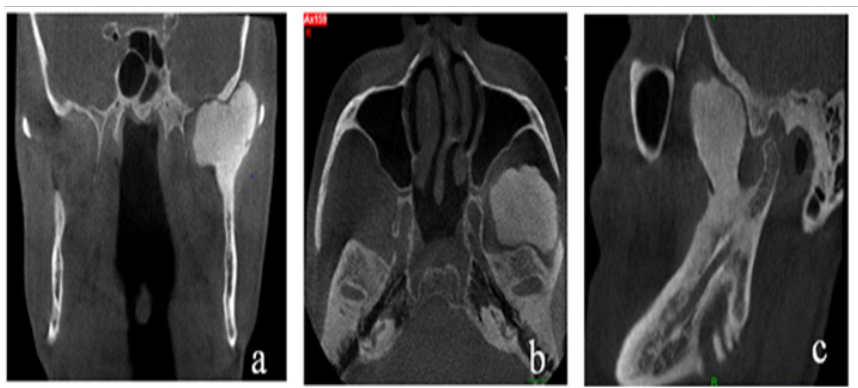

Figure 3 CBCT images showes a mushroom shaped hyperplastic enlargement of the coronoid process which causes resorption under the bones of the skull base.A) coronal, B) axial, C) sagittal sections.

\section{Discussion}

AlthoughOC is rarely seen in the facial bones and skull base, it has been reported in the maxillary sinüs and in different parts of the mandible, such as the condyle, ramus, body, and symphyseal region. ${ }^{8,9}$ It is a stemless lesion composed of bone coated with a cartilaginous capsule that commonly seen the coronoid and condylar process within the facial bones. ${ }^{3}$

There are different hypotheses regarding the etiology, but none of them has been proved. The most popular etiologic hypotheses are previous childhood trauma and hyperactivity of temporal muscle. Although it is known to occur from metaplastic cartilage composed by periosteum, it has been reported that excessive stress caused by tension of the temporalis muscle might be the reason for this condition. ${ }^{10,11}$ This may explain the growing tendency in the coronoid process of the mandible.

Restricted mouth opening is the main clinical symptom of OC. Lateral deviation toward the affected side is frequently found. Pain and disocclusion are uncommon clinical symptoms. ${ }^{12}$ In our case, there were no complaints and another clinical findings but the limitation of mouth opening.

In the radiologic diagnosis, panoramic radiography and Water's projection are useful. Although the panoramic radiography is a widely used screening modality, the interpretation may be difficult due to the superimposition area of the bone lesion and posterior direction of the maxillary bone. Three-dimensional reconstruction by $\mathrm{CBCT}$ is the gold standard test. CBCT provides anatomical details and visualizes abnormalities of tissues and it clarifies its shape, composition, location and relationships with the neighboring structures. CBCT is essential to determine the exact extent of the lesion., ${ }^{713}$

Totsuka et al., ${ }^{14}$ reported that computed tomography (CT) represented enlargement of the coronoid process and deformity of the surrounding bones. Additionally it revealed the shape of the enlarged coronoid process and that of the replaced surrounding bones. Kerscher et al., ${ }^{12}$ reported that only computed tomography can displayed the certain shape of the enlarged coronoid process and the space between the coronoid process and surrounding bones. ${ }^{12}$ Besides that, varied authors have reported the usefulness of CT imaging. ${ }^{7,8}$ Because of this, in the present case we could not reach the diagnosis of $\mathrm{OC}$ with based on panoramic radiography alone. We also used CBCT imaging to confirm the presence of a mass with the same morphological characteristics as those described in previous reports. CBCT provided us to determine the size of the tumor and its relationship to nearby structures.

While CBCT is the gold standard for preoperative diagnosis, histopathological analysis is required for final diagnosis. Removal of the enlarged portion of the coronoid process is the certain treatment. After surgically recurrence is rare. ${ }^{8}$

OC should be distinguished from benign situations such as condylar hyperplasia, osteoma, chondroma, chondroblastoma, giant cell tumour, benign osteoblastoma and malignant lesions such as fibro sarcoma and chondrosarcoma. ${ }^{15}$

Consequently, clinical features such as occurrence advanced age, rapid growth and invasion to the surrounding structures may be redolent of malignant change. A careful assessment of the patient's history supplies important information for the diagnosis and treatment of OC.CBCT is a very useful method for diagnosis of lesions of the coronoid process and essential for completing the diagnosis, for determining the size of the tumor and its relationship to nearby structures, and for surgical planning.

\section{Acknowledgements}

None.

\section{Conflicts of interest}

The author declares no conflict of interest.

\section{References}

1. Karras SC, Wolford LM, Cottrell DA. Concurrent osteochondroma of the mandibular condyle and ipsilateral cranial base resulting in temperomandibular joint ankylosis: report of a case and review of the literature. J Oral Maxillofac Surg. 1996;54(5):640-646.

2. Losa-Munoz PM, Burgueno-Garcia M, Gonzalez-Martin-Moro J, et al Osteochondroma of coronoid process: a rare etiology of jacob disease. Craniomaxillofac Trauma Reconstr. 2014;7(4):306-309.

3. Ortakoglu K, Akcam T, Sencimen M, et al. Osteochondroma of the mandible causing severe facial asymmetry: a case report. Oral Surg Oral Med Oral Pathol Oral Radiol Endod. 2007;103(5):e21-e28.

4. Villanueva J, Gonzalez A, Cornejo M, et al. Osteochondroma of the coronoid process. Med Oral Patol Oral Cir Bucal. 2006;11(3):E289-E291.

5. Ward BB, Pires CA, Feinberg SE. Osteochondromas of the mandible: case reports and rationale for treatment. J Oral Maxillofac Surg. 2005;63(7):1039-1044.

6. Takahashi A, Hao-Zong W, Murakami S, et al. Diagnosis of coronoid process hyperplasia by three-dimensional computed tomographic imaging. Dentomaxillofac Radiol. 1993;22(3):149-154.

7. Etoz OA, Alkan A, Yikilmaz A. Osteochondroma of the mandibular coronoid process: a rare cause of limited mouth opening. Br J Oral Maxillofac Surg. 2009;47(5):409-411.

8. Emekli U, Aslan A, Onel D, et al. Osteochondroma of the coronoid process (Jacob’s disease). J Oral Maxillofac Surg. 2002;60(11):1354-1356. 
9. Yesildag A, Yariktas M, Doner F, et al. Osteochondroma of the coronoid process and joint formation with zygomatic arch (jacob disease):report of a case. Eur J Dent. 2010;4(1):91-94.

10. Roychoudhury A, Gupta YK, Parkash H, et al. Jacob disease:report of a case and review of the literature. J Oral Maxillofac Surg. 2002;60(6):699-703.

11. Wolford LM, Mehra P, Franco P. Use of conservative condylectomy for treatment of osteochondroma of the mandibular condyle. J Oral Maxillofac Surg. 2002;60(3):262-268.

12. Kerscher A, Piette E, Tideman H, et al. Osteochondroma of the coronoid process of the mandible. Report of a case and review of the literature. Oral Surg Oral Med Oral Pathol. 1993;75(5):559-564.
13. Avinash KR, Rajagopal KV, Ramakrishnaiah RH, et al. Computed tomographic features of mandibular osteochondroma. Dentomaxillofac Radiol. 2007;36(7):434-436.

14. Totsuka Y, Fukuda H, Iizuka T, et al. Osteochondroma of the coronoid process of the mandible. Report of a case showing histological evidence of neoplasia. J Craniomaxillofac Surg. 1990;18(1):27-32.

15. Kumar A, Rastogi S, Modi M, et al. Osteochondroma of the mandibular condyle. Indian J Dent Res. 2011;22(4):616. 